\title{
Pyogenic granuloma mimicking a colon cancer
}

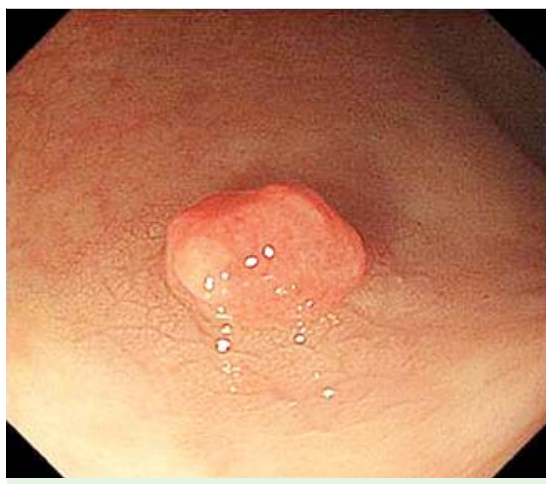

Fig. 1 Colonoscopy showed a reddish, irregular shaped, semipedunculated polyp in the rectum, approximately $10 \mathrm{~mm}$ in diameter.

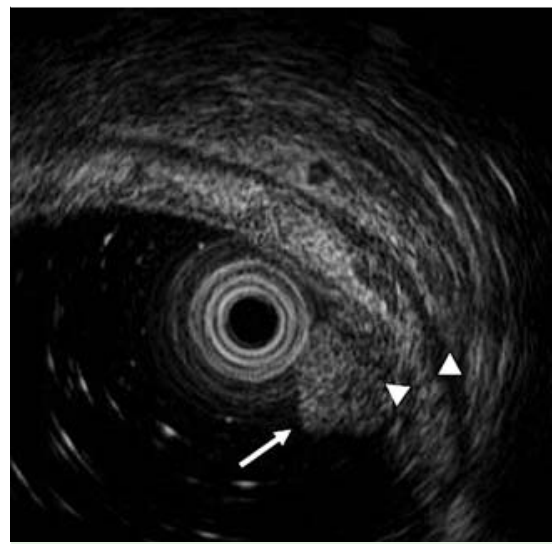

Fig.4 Endoscopic ultrasound revealed that the lesion was confined to the mucosal layer (arrow) and that the submucosal layer (arrow heads) was intact.

A 59-year-old man with a history of chronic myelogenous leukemia underwent colonoscopy because of altered bowel habit. Conventional colonoscopy showed a reddish, irregular shaped, semipedunculated polyp in the rectum, approximately $10 \mathrm{~mm}$ in diameter $(\bullet$ Fig. 1$)$. Magnifying endoscopy with indigo carmine revealed a smooth surface without mucosal pits ( Fig. 2). Magnifying endoscopy with narrow band imaging showed many microvessels with a congested network pattern ( Fig.3). A colon cancer was considered by colonoscopic findings. However, histopathology of biopsies showed inflammatory granulation tissue and no evidence of cancer. Endoscopic ultrasound revealed that the lesion was confined to the mucosal layer and that the submucosal layer was intact ( Fig. 4). The lesion was removed by endoscopic muco-

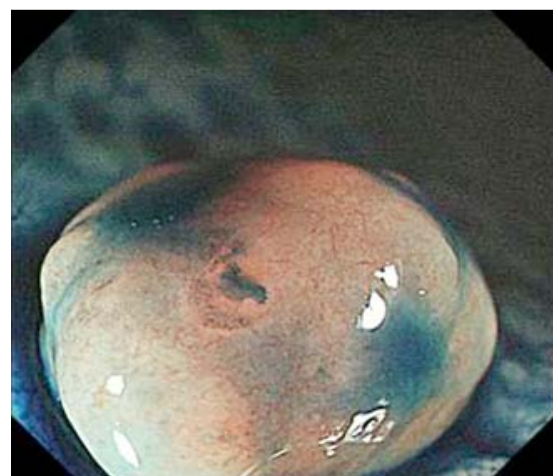

Fig. 2 Magnifying endoscopy with indigo carmine revealed a smooth surface without mucosal pits.

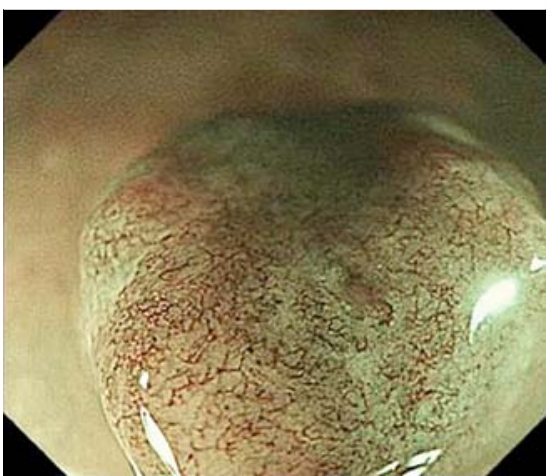

Fig. 3 Using narrow band imaging, many microvessels with a congested network pattern were seen.
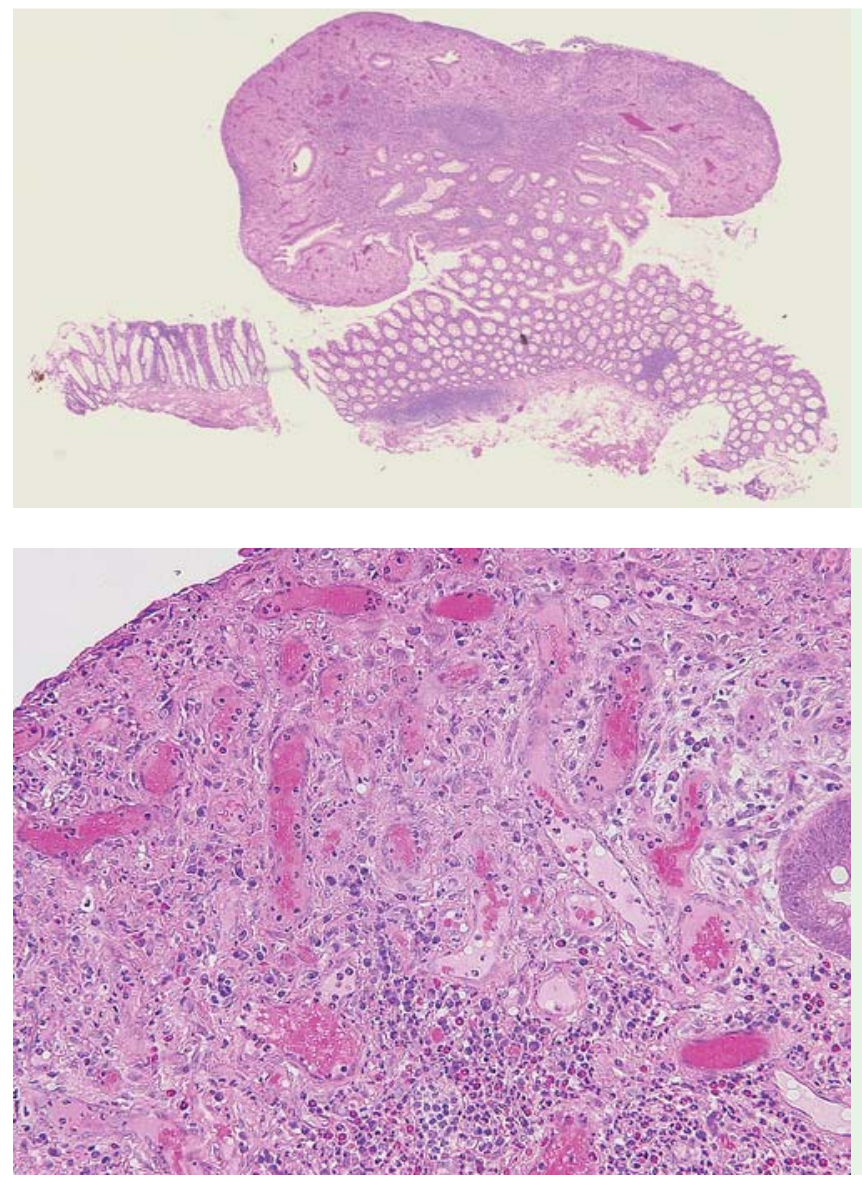

Fig. 5 Low-power microscopic view of the resected specimen. The lesion consisted of inflammatory granulation tissue and was covered with regenerating epithelium. sal resection for accurate diagnosis. Histopathologically, the lesion consisted mainly of inflammatory granulation tissue and was covered with regenerating epithelium. It was diagnosed as a pyogenic granuloma ( Fig. 5 and $\bullet$ Fig. 6 ).

Pyogenic granuloma is a benign lesion of unknown etiology [1]. It is common on the skin and oral mucosal surfaces, but ex- tremely rare in the gastrointestinal tract, especially in the colon [2]. Clinically, it can mimic a colon cancer because of the irregular shape [3]. Gastrointestinal pyogenic granuloma is usually covered with thick exudate [4] and its mucosal surface cannot be observed. This case was not covered with thick exudate enabling the surface to be observed in detail by magni- 
fying endoscopy. To our knowledge, this is the first report of a case of colonic pyogenic granuloma observed by magnifying endoscopy. The histopathological characteristics of pyogenic granuloma are proliferation and lobular arrangement of capillaries with an inflamed and edematous stroma [5]. In this case, the capillaries in the pathology report corresponded with magnifying endoscopy findings. Pyogenic granuloma should be considered when an irregular shaped colon polyp has a congested microvascular network and lacks mucosal pits.

Endoscopy_UCTN_Code_CCL_1AD_2AC

Competing interests: None
Yasuhiko Hamada', Kyosuke Tanaka', Syunsuke Tano ${ }^{1}$, Takashi Kitade ${ }^{1}$, Masaki Katsurahara', Noriyuki Horiki ${ }^{1}$, Yoshiyuki Takei $^{2}$

${ }^{1}$ Department of Endoscopic Medicine, Mie University Hospital, Tsu, Japan

${ }^{2}$ Department of Gastroenterology, Mie University Graduate School of Medicine, Tsu, Japan

\section{References}

1 Val-Bernal JF, Mayorga M, García-Somacarrera $E$. Pyogenic granuloma of the large intestine: case report and review of reported cases in the adult. Pathol Res Pract 2012; 208: $687-690$

2 Thibault A, Lavergne-Slove A, Soyer $P$ et al. Pyogenic granuloma of the colon. Endoscopy 2012; 44: E155-156

3 Hocke $M$, Bosseckert $H$. Incorrect macroscopic diagnosis of colonic carcinoma made at endoscopy. Endoscopy 2004; 36: 668

4 Hosono T, Kawamura T, Murakami K et al. A case of pyogenic granuloma of the descend- ing colon [in Japanese]. Jpn J Gastroenterol Surg 2011; 44: 1039-1046

5 Carmen González-Vela M, Fernando Val-Bernal J, Francisca Garijo $M$ et al. Pyogenic granuloma of the sigmoid colon. Ann Diagn Pathol 2005; 9: 106-109

\section{Bibliography}

DOI http://dx.doi.org/

10.1055/s-0034-1364955

Endoscopy 2014; 46: E153-E154

(c) Georg Thieme Verlag KG

Stuttgart · New York

ISSN 0013-726X

\section{Corresponding author}

\section{Yasuhiko Hamada, MD, PhD}

Department of Endoscopic Medicine Mie University Graduate School of Medicine 2-174 Edobashi

Mie, $514-8507$

Tsu

Japan

Fax: +81-59-2315200

hamayasu0828@kxe.biglobe.ne.jp 